\title{
A TELENOVELA ENQUANTO "FOLHETIM ELETRÔNICO" REPRESENTATIVO DO COTIDIANO NACIONAL E SUA POTENCIALIDADE COMUNICATIVA
}

\author{
Rondinele Aparecido RIBEIRO ${ }^{1}$ \\ Universidade Estadual Paulista - UNESP \\ rondinele-ribeiro@bol.com.br
}

Resumo: Para Lopes (2010), as mídias fornecem um grande material para o processo de mediação social, servindo também como instâncias privilegiadas para fornecer referências para o sujeito. Pode-se falar que as mídias, nesse cenário pós-moderno, agem como um novo campo de socialização. Um dos gêneros midiáticos de maior importância para o Brasil é a telenovela, que se constituiu como um gênero por excelência devido a sua especificidade de atingir a todas as classes sociais. A partir dessa constatação, o presente artigo contempla a telenovela como um objeto privilegiado acerca da cultura e da sociedade contemporânea brasileira, encarando-a como uma forma de transmissão cultural, que promove amplamente o processo de criação de identidades. Para tanto, o trabalho avança também na hipótese de a telenovela conter propriedades pedagógicas e sustenta a tese desse produto funcionar como um recurso comunicativo, tal como defende Lopes (2014).

Palavras-chave: Telenovela. Identidade. Ficcionalidade. Representatividade.
Resumen: Para Lopes (2010), los medios de comunicación proporcionan un gran material para el proceso de la mediación social, sirviendo también como instancias privilegiadas para proporcionar referencias para el sujeto. Usted puede hablar con los medios de comunicación, en este escenario post-moderna, actuar como un nuevo campo de socialización. Uno de los géneros de los medios más importantes para Brasil es la telenovela, que se constituyó como un género por excelencia debido a su especificidad para llegar a todas las clases sociales. A partir de esta evidencia, este artículo incluye la telenovela como un objeto privilegiado de la cultura brasileña y la sociedad contemporánea viéndolo como una forma de transmisión cultural, que en gran medida promueve el proceso de creación de identidad. Por lo tanto, el trabajo también avanza la hipótesis de la telenovela contienen propiedades pedagógicas y apoya la opinión de que la función del producto como recurso comunicativo, como aboga Lopes (2014).

Palabras clave: Soap Opera. Identidad. Ficcionalidad. Representatividad.

\footnotetext{
${ }^{1}$ Mestrando em andamento em Letras pela Universidade Estadual Paulista Júlio de Mesquita Filho, UNESP Licenciado em Letras-Literatura pela UENP/CJ. Tem Especialização em Cultura, Literatura Brasileira e Língua Portuguesa. Acadêmico do 7o período do curso de Pedagogia (UCESP). Acadêmico do 4 으 período do curso de Direito (FANORPIUNIESP).
} 


\section{Introdução}

A televisão está presente no Brasil desde 1950 e se notabiliza por ser o meio de comunicação mais difundido na sociedade. Como postula Sadek (2008), o Brasil foi um dos primeiros países a contar com a transmissão de televisão, constituindo-se, na verdade, como um ato bastante ousado. Vale acrescentar que a primeira transmissão no Brasil, ocorrida em 18 de setembro de 1950, foi marcada pelo caráter amador, uma vez que não se teve um planejamento mais sério. Visto pela crítica como uma das criações mais importantes do século XX, esse meio de comunicação atinge quase $100 \%$ dos lares brasileiros.

Rocco (1994), ao teorizar sobre a televisão, assevera que, ao lado do computador, ela ocupa o posto de invento mais importante do século XX, pelo fato de ter sido responsável por definir novas formas de organização social, podendo ainda conferir a grande responsabilidade de se constituir em meio formativo e informativo da sociedade. Como esclarece a estudiosa, "o veículo se tornou parte integrante, se não integradora, do cotidiano de todas as pessoas em praticamente todo o mundo" (ROCCO, 1994, p. 55).

Na visão de Wolton (1996), a televisão forma um verdadeiro laço indispensável numa sociedade marcada pelo isolamento do indivíduo. A televisão é "companheira das nossas solidões, testemunha de nossa vida cotidiana, memória do tempo imóvel" (WOLTON, 1996, p.11). Enquanto suporte, sabe-se que apresenta inúmeros programas e formatos. Arlindo Machado (2000), ao estudar as especificidades da televisão, dividiu os gêneros televisuais em sete: as formas fundadas no diálogo, as narrativas seriadas, o telejornal, as transmissões ao vivo, a poesia televisual, o videoclipe e outras formas musicais. $\mathrm{O}$ autor destaca também três formas principais de narrativas seriadas. Nas palavras do teórico, "é o caso dos teledramas, telenovelas e de alguns tipos de séries ou minisséries." (MACHADO, 2000, p.84).

Sem sombra de dúvidas, dentre os programas de maior sucesso na televisão, está a telenovela, produto de ficção midiática, que teve suas primeiras experiências no Brasil no ano de 1951, com a exibição de Sua Vida me Pertence. De um produto desqualificado do ponto de vista da crítica inicial, esse produto, na atualidade, ganhou status bastante peculiar passando a ser o programa de maior sucesso da televisão brasileira, constituindo-se num verdadeiro produto cultural sobre a nação. Nesse sentido, sua trajetória se coaduna com a trajetória rumo à modernização experimentada pelo Brasil. 
Na atualidade, como esclarece Lopes (2014), a televisão é "intensa na sociedade brasileira, devido a sua capacidade de alimentar um repertório compartilhado de sentidos por meio do qual pessoas de classes sociais, gerações, sexos, etnias e regiões diferentes se posicionam e se reconhecem umas às outras." (LOPES, 2014, p.02). A partir dessas considerações, o presente artigo objetiva recuperar a gênese da telenovela e situar sua importância como produto cultural midiático que participa ativamente do processo de (re)criação de identidade(s). Para tanto, o trabalho avança também na hipótese de a telenovela conter propriedades pedagógicas e sustenta a tese de esse produto funcionar como um recurso comunicativo, tal como defende Lopes (2014).

\section{O percurso formativo do produto de mídia televisiva}

A telenovela ocupa o posto de grande promotora da ficção no cenário pós-moderno. Esse produto notabiliza-se como um dos programas de televisão com formato mais caro. Basta uma simples constatação na mídia impressa ou mesmo televisiva para se perceber que se trata de um formato que logra muito sucesso entre os brasileiros, atraindo milhões de pessoas que acompanham diariamente o desenrolar da história. Pode-se afirmar que ela é um gênero híbrido, já que sua origem está atrelada a diversas matrizes, tais como a narrativa folhetinesca, o melodrama, a radionovela e a soap opera. Dessa forma, pode-se perfeitamente compreender que a telenovela consagrou-se como um produto de forte aceitação popular e se notabiliza como gênero mais lucrativo da televisão brasileira.

A estudiosa Renata Pallottini define esse produto ficcional como

[...] uma história contada por meio de imagens televisivas, com diálogo e ação, criando conflitos provisórios e definitivos [...]. A telenovela se baseia em diversos grupos de personagens e lugares de ação, grupos que se relacionam interna e externamente - ou seja, dentro do grupo e com os demais grupos; supõe a criação de protagonistas, cujos problemas assumem primazia na condução da história (PALLOTTINI, 2012, p.35).

Muito já se teorizou acerca das narrativas e de sua importância para a humanidade. A telenovela corresponde ao modelo narrativo da contemporaneidade, já que seu fundamento parte de uma necessidade humana: o gosto pela narração. Tanto que o estudioso Carlos Sadek (2008, 
p.17) assevera que "a telenovela pode ser incluída em umas das mais antigas tradições da espécie humana: a de contar e ouvir histórias.”.

A telenovela vem sendo exibida ininterruptamente no Brasil desde 1951, sendo lícito compreender que a trajetória do produto se confunde com a do suporte televisivo. Ao teorizar acerca do enorme sucesso que as telenovelas logram no país, a estudiosa Claudia Mogadouro (2007) explica que tal produto artístico constitui-se como uma narrativa, a qual, por um percurso bastante diferente de outros países latino-americanos, foi alçada ao posto de principal e mais lucrativo produto da ficção seriada. De um produto menor na grade da programação televisiva, a telenovela passou a ser vista como o produto de mídia mais importante da televisão brasileira, ganhando status de uma produção bem elaborada e que dialoga diretamente com o cotidiano do país. Por esse motivo, autores como Lopes $(2002,2003)$ sustentam que a telenovela se notabiliza como uma narrativa sobre a nação.

Assim, nas palavras de Lopes (2003, p.07), “é possível afirmar que a telenovela no Brasil conquistou reconhecimento público como produto artístico e cultural e ganhou visibilidade como agente central do debate sobre a cultura brasileira e identidade do país.”. A teórica credita o sucesso do gênero no país, afirmando ser a telenovela um dos fenômenos de maior representação da modernidade brasileira, constituindo-se num verdadeiro fenômeno cultural, que exporta esse produto, nutrindo o ideário mundial com as produções nacionais.

Ao considerar a telenovela como um grande fenômeno da cultura brasileira, a autora pronuncia-se da seguinte forma:

Ela também pode ser considerada um dos fenômenos mais representativos da modernidade brasileira, por combinar o arcaico e o moderno, por fundir dispositivos narrativos anacrônicos e imaginários modernos e por ter a sua história fortemente marcada pela dialética nacionalização-massmediação (LOPES, 2003, p.17).

Como esclarece a autora, para se adaptar do rádio para a televisão, a telenovela transportou do rádio tanto a técnica como autores, diretores e atores. Nesse processo de adaptação e formatação do gênero no Brasil, não se pode se esquecer da influência do melodrama latino-americano, que, em muito, ajudou a consolidar o gênero.

Claudia Mogadouro (2007), ao tecer considerações sobre a telenovela, assim se pronuncia: 
A telenovela é o produto cultural mais popular e lucrativo da televisão brasileira, consumida por todas as camadas da nossa sociedade. Embora tenha sua origem numa estrutura essencialmente melodramática, esse gênero percorreu um caminho muito interessante no Brasil, pois buscou uma forma própria de narrativa popular, pautada nas relações do cotidiano, agregando realismo e críticas sociais, construindo um produto extremamente representativo da modernidade brasileira, por juntar o moderno e o arcaico, um típico produto da hibridização cultural (MOGADOURO, 2007, p.88-89)

A partir dos postulados da estudiosa em questão, entende-se claramente que a telenovela, enquanto produto de mídia, é o produto mais consumido e o que mais agrega valores à sociedade, sendo um corpus privilegiado na atualidade, balizando questões inerentes à formação e (re)construção de identidade(s). Esse gênero, não resta dúvida, passou a se constituir numa verdadeira narrativa ficcional sobre o país, constituindo-se como um precioso instrumento de integração nacional, na medida em que sua trajetória, enquanto produto cultural, permite associar sua evolução temática com o processo de abertura política e rearranjo econômico pelos quais o Brasil estava passando.

A partir do exposto, é lícito afirmar que nas últimas quatro décadas, a telenovela alterou profundamente sua forma de composição bem como sua estrutura temática, servindo, no Brasil, como um produto que vai muito além de ato levar acesso à ficção, mas sim um produto que muito serviu (e continua servindo) para abordar as amplas transformações sociais pelas quais o país passou e passará. Seu tecido pode se alçado ao posto de uma grande crônica representativa do cotidiano nacional, que se constitui em um verdadeiro palco para problematizar e interpretar o país. Uma sistematização do estudo das telenovelas

Para a estudiosa Claudia Mogadouro (2007, p.88-89), a telenovela se constitui como um produto cultural de caráter mais popular e lucrativo da tevê brasileira. Para explicar esse ponto de vista, a autora volta-se para a questão do consumo, já que a telenovela é um produto cultural de forte aceitação, atingindo a todos os lares, independentemente do rótulo de classes. Dessa forma, esse produto de ficção seriada, constituído pela forte tradição narrativa que impera na sociedade e por um conjunto de referências híbridas, tais como o melodrama, o folhetim, a soap opera e a radionovela, apresenta um desenrolar bastante singular no Brasil.

Como se sabe, esse produto ficcional, inicialmente, não contou com uma recepção favorável da crítica especializada, que lhe atribuía o rótulo de produto alienante, melodramático que retratava temáticas óbvias. Ao se posicionar acerca do sucesso obtido pelas produções contemporâneas, a 
autora sustenta que a telenovela "[...] buscou uma forma própria de narrativa popular, pautada nas relações do cotidiano, agregando realismo e críticas sociais, construindo um produto extremamente representativo da modernidade brasileira [...]" (MOGADOURO, 2007, p.88-89).

A estudiosa Maria Imacolatta Vassolo Lopes, em seu artigo intitulado "Telenovela como Recurso Comunicativo", de (2009), propõe uma divisão para a história da telenovela brasileira, que, segundo a autora, passa por 03 fases muito bem definidas: a fase sentimental (1950-1967), a fase realista (1968-1990), e, por fim, a fase naturalista, datada desde os anos 1990.

Lopes enquadra como fase sentimental o conjunto de produções compreendido entre 1950 a 1967, na fase incipiente da televisão. Assim, pode-se apontar como características preponderantes de tais produções o aspecto extremamente melodramático, assentado em uma visão estritamente maniqueísta, a qual não mantinha relação alguma com a sociedade.

As primeiras experiências com o formato no Brasil remontam ao ano de 1951, ano em que foi exibida a telenovela Sua Vida me Pertence. Nessa fase incipiente, o formato dominante das produções era pautado pela forte improvisação, pela ausência de uma linguagem técnica e pelo caráter evasivo notoriamente melodramático. Essa telenovela é considerada pela crítica como a primeira experiência do gênero no Brasil, todavia, cumpre o dever de esclarecer que nessa fase pioneira, tais produções não eram os produtos mais rentáveis da televisão, tampouco eram vistos com bons olhos pelo meio acadêmico. Pesava-lhe o rótulo de ser um produto de viés evasivo, alienante, melodramático e destinado às mulheres. Como esclarece Esther Império Hamburger, “[...] inicialmente feita ao vivo, não era diária, não ocupava o horário nobre, não era o programa mais lucrativo ou aquele em que as emissoras investiam maiores recursos." (HAMBURGER, 2011, p. 67).

A estudiosa Maria Aparecida Baccega (2013, p.31) explica que as primeiras produções contavam com um viés fortemente maniqueísta. Por esse motivo, os personagens eram muito bem definidos em bons e maus, os diálogos eram pobres e as situações se baseavam em estereótipos já consagrados de uma sociedade ainda patriarcal. Dessa forma, o arquétipo das primeiras telenovelas brasileiras seguia a seguinte estrutura: o primado do sentimento, o conflito amoroso era sempre o fio condutor de qualquer novela tal qual no romance de folhetim.

Alterações profundas nesse gênero só aconteceram a partir de 1963 com a inovação implementada pela TV Excelsior a partir da atitude de Edson Leite, que, em uma visita à Argentina, 
se deparou com o hábito de histórias parcelas diárias. O superintendente resolveu implantar esse mesmo hábito no Brasil e importou o roteiro de uma telenovela, aqui adaptado com o nome de 25499 Dá Ocupado.

Seguindo o cânone estabelecido por Lopes, a autora denomina de Fase Realista aquela iniciada a partir de 1968. Pode-se dizer que, a partir dessa data, a telenovela, que, antes, era marcada por seu caráter evasivo, passou a retratar e a dialogar diretamente com o cenário nacional, nutrindo os espectadores de referências notoriamente nacionais, o que muito contribui para incutir nos telespectadores o sentido de pertencimento. Nesse sentido, a telenovela passou a servir como meio de representação e de diálogo com uma nação que se modernizava, ao passo que experimentava uma situação sociopolítica bastante significativa. O cenário político era marcado pela presença de um governo ditatorial. Por sua vez, no plano social, pode-se citar como marco o ingresso do país no cenário global bem como a suplantação de sua condição agrária e o intenso processo de metropolização.

Ao se posicionar sobre as produções dessa fase, Lopes explica que a telenovela "[...] se estruturou em torno de representações que compunham uma matriz imaginária capaz de sintetizar a sociedade brasileira em seu movimento modernizador.” (LOPES, 2009, p.23-24).

A telenovela Beto Rockfeller, de Braulio Pedroso, exibida pela extinta TV Tupi, alterou profundamente o cenário ora apresentado, uma vez que, recorrendo a cenas do cotidiano, passou a encantar o público que se viu representado. A crítica confere a essa obra o status de trama revolucionária, por empregar um protagonista anti-herói. A obra também colaborou com a mudança na recepção, já que seduziu o público masculino.

Tais características, como destaca Ester Hamburger (2005), estendem-se para as novelas produzidas nos anos 80 , ou seja, perspectiva crítica acerca da realidade brasileira. Assim, percebese que esse gênero contribui de maneira profícua para o entendimento do contexto social brasileiro, podendo-se dizer que elas cumprem um enorme serviço de formação e de representação do brasileiro, ao polarizar, em seu discurso, temáticas extremamente complexas, como a reconfiguração do lar, a alteração do papel da mulher na sociedade, as questões ligadas à política. De fato, como postula Hamburger (2011), o gênero é responsável pela difusão da imagem de um país que se modernizou. 
Por fim, a última fase compreendida pela estudiosa como fase naturalista, tem-se a forte presença de elementos realistas que caracterizaram a fase anterior com a diferença de que, na atual fase, a verossimilhança é atingida quando se empregam temáticas cada vez mais sociais, que mantêm um diálogo constante com a realidade. Para Lopes (2009), a telenovela é um produto que foi alçado ao carro chefe da indústria televisiva, o que lhe permitiu se constituir num verdadeiro espaço de problematização do Brasil, retratando aspectos ligados à intimidade, bem como problemas sociais. Pela profundidade dos temas retratados e pelo serviço de formativo que prestam à nação, é indiscutível que a telenovela deixou de ocupar o posto de mero entretenimento para se consolidar numa narrativa acerca da nação.

A esse respeito, valem as pontuações de Lopes:

Alçada à posição de principal produto de uma indústria televisiva de grandes proporções, a novela passou a ser um dos mais importantes e amplos espaços de problematização do Brasil, indo da intimidade privada aos problemas sociais. Essa capacidade sui generis de sintetizar o público e o privado, o político e o doméstico, a notícia e a ficção, o masculino e o feminino, está inscrita na narrativa das novelas que combina convenções formais do documentário e do melodrama televisivo (LOPES, 2009, p.06).

Pode-se corroborar, então, nas palavras de Lopes (2009, p.06), que a novela tornou-se uma forma de narrativa sobre a nação e um modo de participar dessa nação imaginada, ao passo que promove amplamente o processo de identificação dos telespectadores com os personagens num processo em que o real e o ficcional se misturam. Pode-se afirmar também que as telenovelas promovem alterações de comportamentos, infiltrando-se no cotidiano das pessoas, tornando-se onipresente na vida do telespectador.

Como uma característica dessa fase, Lopes defende que a telenovela deve ser vista como um recurso comunicativo, ou seja, “[...] identificá-la como narrativa na qual se conjugam ações pedagógicas tanto implícitas quanto deliberadas que passam a institucionalizar-se em políticas de comunicação e cultura no país" (LOPES, 2009, p.32).

\section{A telenovela enquanto construtora do senso de cidadania}

Enquanto objeto de estudo acadêmico, a telenovela foi legitimada como campo fértil de estudo apenas nos últimos quarenta anos. Na atualidade, esse produto ficcional é encarado como o 
mais promissor da televisão, veículo que responde por ser a grande promotora de ficção na contemporaneidade, sendo lícito atribuir-lhe a denominação de "folhetim eletrônico".

Se comparada à década de 1970, período em que a televisão ainda não atingia ampla cobertura nos lares brasileiros devido ao preço, a partir dos anos 80, essa situação começa a se alterar, uma vez que a televisão passa a estar presente em um número maior nas casas dos brasileiros. Assim, a partir da década de 1980, o país passou a contar com tramas que não mais ficavam tão restritas ao domínio feminino. Merece ser comentado ainda que esse produto foi-se tornando uma verdadeira "vitrine cultural", sobretudo a partir da década já apontada, que assistiu a uma modernização ainda maior das produções, que passaram a empregar explicitamente a temática política representada por personagens masculinos. Vale acrescentar que tal abordagem agora difere da década anterior pelo fato de o país não contar mais com a censura, o que permitiu às telenovelas do período representar a ditadura de uma maneira mais livre.

Nessa década, a estrutura melodramática mantém-se, mas com contornos menos exagerados. Entre os inúmeros fatos políticos que ocorreram, podem ser apontados o processo de redemocratização do país, a promulgação de uma nova Constituição pautada no Estado Democrático de Direito e anistia. Pode-se citar também a situação caótica do país no plano econômico, marcado, sobretudo, por altas taxas de inflação que assombravam os brasileiros.

Enquanto estimuladora do senso de cidadania, as narrativas realistas e naturalistas parecem ser um prolongamento do noticiário global ao incorporar, em suas narrativas, vários núcleos cujos dilemas marcam uma referência às problemáticas enfrentadas pelos brasileiros. Nesse sentido, tem-se uma perfeita simbiose entre o universo da realidade e da ficcionalidade. Residem, então, nesses aspectos, as potencialidades desse gênero, já que pode ser considerado um nutriente ficcional, formativo e informativo da sociedade.

A partir da inserção desse viés mais naturalista nas ficções televisivas, pode-se entender que esse vasto conjunto de referências narrativas passam a ser um nutriente na memória do receptor. Notoriamente, a telenovela é alçada ao status de objeto artístico e estético, notabilizandose como fator de humanização, posto que pode educar e edificar. Enquanto objeto estético, propicia ao leitor entrar em contato com um mundo que não é o seu, servindo como um agente de ampliação dos horizontes de expectativas. Nesse sentido, estimula o senso crítico e o senso de cidadania, 
servindo como amplo espaço de reflexão por representar os conflitos humanos e torná-los próximos da sociedade.

\section{Ao abordar as potencialidades da telenovela, Lopes esclarece:}

Acreditamos que abordar a telenovela como recurso comunicativo é identificá-la como narrativa na qual dispositivos discursivos naturalistas ou documentarizantes passam a ser deliberadamente explicitados e combinados com diversificações da matriz melodramática da telenovela (LOPES, 2014, p.05).

A narrativa televisiva é capaz de representar temáticas cada vez mais cotidianas do universo brasileiro, que muito serve como um estímulo ao senso crítico e propicia um amplo espaço de reflexão, o que Lopes $(2009 ; 2014)$ define como potencialidade de a telenovela constituir-se como uma agenda setting, justamente por servir como espaço de reflexão, por representar os conflitos humanos e torná-los próximos dos receptores, e, na maioria das vezes, servindo como uma verdadeira prática de esclarecimento de condutas as quais nutrem a referência do telespectador.

Para Lopes (2014), o telespectador vive imerso numa verdadeira cultura da comunicação, que está assentada na percepção que se tem sobre o outro, bem como no reconhecimento do indivíduo como componente principal do agir comunicativo.

Nas palavras da autora:

É dentro desse universo de sentidos que podemos conceber a institucionalização singular da telenovela brasileira na cultura e na sociedade como um recurso ou uma "alavanca" que pode ser ativada na persecução da cidadania cultural, no reconhecimento das forças cooperativas de existência bem como dos conflitos que emergem nessa caminhada. (LOPES, 2014, p.07).

Nesse sentido, as telenovelas, enquanto componente máximo da sociedade audiovisual, atuam como elemento de socialização e fonte pedagógica, sobretudo por esclarecer condutas, legar valores e informações, comportando-se como grande fator de emancipação.

Essa condição da narrativa midiática, a qual se notabiliza por travar um diálogo amplo com a realidade, faz com que ela se converta num espaço amplo e privilegiado para retratar temáticas sociais, bem como ficcionalizar dramas inerentes aos brasileiros. Ademais, é essa especificidade que possibilita o surgimento de novos modos de perceber a realidade, bem como servir como uma 
iniciativa ampla com a finalidade de informar o receptor, estimulando-o a uma reação (ou até mesmo uma ação) retratada no enredo da telenovela.

\section{Considerações finais}

A temática envolvendo mídia e seus contornos acadêmicos vem sendo moldada desde o momento em que se constatou a possível influência delas na formação da subjetividade do indivíduo. Falar sobre a ascensão das mídias e de seus contornos é reportar ao seu desenvolvimento ocorrido, sobretudo, na década de 1940, num contexto de rearranjo industrial.

$\mathrm{Na}$ atualidade, a mídia é entendida como uma forma de cultura simbólica estruturada em contextos sociais específicos, notabilizando-se como uma forma de transmissão cultural. Enquanto objeto privilegiado de construção de uma narrativa sobre o país, a telenovela tem se constituído por tramas cada vez mais naturalistas ao explorar temáticas ligadas ao cotidiano do brasileiro. Nesse sentido, tal produto tem alcançado a aceitação das classes mais abastadas, alterando, então, sua condição inicial de produto voltado para as classes menos favorecidas.

É sabido que, enquanto gênero ficcional de televisão, sua produção está entre os produtos mais rentáveis das emissoras. Sua fórmula está embasada num grande mosaico herdado de outros gêneros de cultura popular, tais como melodrama, folhetim, soap opera e radionovela. Sua presença no país desde a implantação da televisão faz com que se torne impossível abordar o gênero sem abordar o suporte (a televisão).

É inegável que o ideal da contemporaneidade sofre grande influência da mídia, que passa a ser a grande fornecedora de material para entretenimento e fruição. Assim, a televisão, por meio da telenovela, veicula costumes e fornece referências de vida de diversos grupos sociais, podendo atuar como uma narrativa promotora do exercício de cidadania ao promover, em suas tramas, situações notoriamente naturalistas.

Enquanto objeto artístico e estético, a telenovela consubstancia-se numa narrativa capaz de materializar as referências histórico-sociais do indivíduo e catapultá-las em suas narrativas repletas de significados e símbolos que acabam por envolver o ser humano na urdidura de seu amargo dia. Outro ponto extremamente importante reside no fato de as mídias estarem ligadas ao processo de fornecimento de referências para o sujeito. Nesse sentido, todo o capital simbólico, como imagens, sons, espetáculos e narrativas, são de extrema importância para a construção do indivíduo como 
sujeito. Ademais, ao fornecer material, dominar o tempo, o lazer, tentar incutir valores, modelar opiniões e comportamentos sociais, e apresentar informações, a narrativa midiática, vista e comentada pela sociedade brasileira, mostra-se um produto cuja narrativa apresenta grande potencialidade para retratar temáticas cada vez mais próximas dos brasileiros, o que serve como instrumento pedagógico ou, ainda, emancipador, na medida em que trata de situações cada vez próximas de seu público-alvo, servindo como recurso comunicativo (conforme esclarece Lopes), ou como fonte promotora do senso de cidadania.

\section{Referências}

HAMBURGER, E. O Brasil antenado: A sociedade da telenovela. Rio de Janeiro: Jorge Zahar, 2005

Telenovelas e Interpretações do Brasil. In Lua Nova: Revista de Cultura e

Política.

Disponível em $<$ http://www.scielo.br/scielo.php?pid=S010264452011000100004\&script=sci_arttext $>$. Acesso em 12/10/14.

LOPES, M. I. V. . Ficção televisiva e identidade cultural da nação. Alceu(PUCRJ), v. 10, p. 05$15,2010$.

Telenovela e direitos humanos: a narrativa de ficção como recurso comunicativo. In: ANAIS INTERCOM- Sociedade Brasileira de Estudos Interdisciplinares da Comunicação. XXXII Congresso Brasileiro de Ciências da Comunicação - Curitiba, PR - 4 a 7 de setembro de 2009.

.Memória e Identidade na Telenovela Brasileira. Disponível em $<$ http://compos.org.br/encontro2014/anais/Docs/GT12_ESTUDOS_DE_TELEVISAO/templatex xiiicompos_2278-1_2246.pdf>. Acesso em 04/05/2016.

.Telenovela brasileira: uma narrativa sobre a nação. Revista Comunicação e Educação. Jan/abr. $2003 . \quad$ Disponível em<http://www.revistas.univerciencia.org/index.php/comeduc/article/viewfile/4195/3934>. Acesso em 05/03/2014.

. Narrativas Televisivas e Identidade Nacional: O Caso da Telenovela

Brasileira. Intercom-XXV Congresso Brasileiro de Ciências da Comunicação Salvador/BA -1 a 5 Set 2002

LOPES, M.I.V. Telenovela como Recurso Comunicativo. Matrizes, v. 3, n.1, 2009. 
MACHADO, A. A Televisão levada à sério. São Paulo: SENAC, 2000.

MOGADOURO, C.A. A Telenovela brasileira: uma nação imaginada. Eco-Pós, v.10, n. 2, p. 85-95, 2007.

PALLOTTINI, R. Dramaturgia de televisão. 2. ed. São Paulo: Boitempo, 2008.

ROCCO, M.T.F. Que pode a escola diante do fascínio da TV. Disponível em<http://www.crmariocovas.sp.gov.br/pdf/c_ideias_09_053_a_062.pdf $>$. Acesso em 12/10/13.

SADEK, J.R. Telenovela: Um olhar do cinema, São Paulo: Summus, 2008.

WOLTON, D. O elogio do grande público: uma teoria crítica datelevisão. São Paulo: Ática, 1996. 